\title{
ANALYSIS OF OCULAR MANIFESTATIONS OF BLUNT TRAUMA TO THE EYE
}

\author{
Udaysridhar Mulgund1, Rajashekhar Dyaberi², Ravishankar Mahalingappa ${ }^{3}$
}

${ }^{1}$ Associate Professor, Department of Ophthalmology, Karnataka Institute of Medical Sciences, Hubli.

${ }^{2}$ Assistant Professor, Department of Ophthalmology, Karnataka Institute of Medical Sciences, Hubli.

${ }^{3}$ Resident (Postgraduate), Department of Ophthalmology, Karnataka Institute of Medical Sciences, Hubli.

\begin{abstract}
BACKGROUND

Ocular trauma remains one of the most significant sight threatening problems in the recent years. Changing life pattern, modernisation, rapid industrialisation and high-speed travel, wide and variable exposure to the surroundings are contributing factors in blunt trauma. Trauma to the eye and adjacent structures requires meticulous examination to determine the loss of vision, range of involvement of extraocular muscles, and extent of injury to the anterior and posterior segment of the eye and extent of injury to other orbital and adnexal tissues which result in suboptimal vision.

Objectives-

1. To determine the common effects of different types of injuries on the ocular structures.

2. To determine and identify the current causes, sites, mechanism and extent of injury to the eye in relation to different levels of trauma.
\end{abstract}

\section{MATERIALS AND METHODS}

A prospective, interventional study was conducted on 100 patients at KIMS, Hubli presenting with blunt ocular trauma from September 2016 to August 2017.

\section{RESULTS}

In our study, the M: F ratio was 5.25:1 (84:16) with clear male preponderance. Age incidence study showed that blunt ocular injuries were common in younger age group comprising of 66 patients $(66 \%)$ i.e. below the age of 35 years (people who are very active and in productive age group). 52 patients (52\%) had occupational injuries of which $70 \%$ were farmers. Object causing blunt injuries are stone $(18 \%)$ and stick (12\%). Ocular structure involved in blunt trauma mainly are: anterior segment injuries- 94 patients (94\%); i.e. conjunctiva- 70 patients $(70 \%)$, lid- 65 patients $(65 \%)$, periorbital lesions- 56 patients (56\%), ecchymosis of periorbital tissue- 42 patients (42\%), lid oedema- 37 patients (37\%), iris involvement- 20 patients (20\%), lens involvement- 15 patients (15\%), cornea involvement- 14 patients (14\%), traumatic miosis- 6 patients (6\%), traumatic mydriasis- 9 patients (9\%); posterior segment- 18 patients (18\%) were involved in which retinal detachment- 4 patients (4\%), macular oedema- 3 patients (3\%) vitreous haemorrhage- 3 patients (3\%) and 2 cases with choroidal rupture were seen.

\section{CONCLUSION}

Our study indicates that ocular lesions with blunt injuries are fairly common. In our study, occupational injuries mainly agriculture related as the cases are from rural areas of North Karnataka. The ocular trauma is associated with varying degrees of loss of vision and earning capacity with social and economic consequences. Early referral, prompt evaluation and treatment will reduce the sight threatening complications in these cases.

\section{KEYWORDS}

Ocular Manifestations, Blunt Trauma, Anterior Segment, Hyphaema, Angle Recession, Retinal Detachment.

HOW TO CITE THIS ARTICLE: Mulgund U, Dyaberi R, Mahalingappa R. Analysis of ocular manifestations of blunt trauma to the eye. J. Evolution Med. Dent. Sci. 2017;6(93):6755-6760, DOI: 10.14260/jemds/2017/1463

\section{BACKGROUND}

Ocular injury is a major health problem in India, blunt trauma being one of the important causes of ocular morbidity and blindness. ${ }^{1}$ Children at play, young men at work, in factories and construction sites, road side falls, high speed travel and Road Traffic Accident, sport injuries, fall on projecting blunt objects and in a rural setup like ours agriculture-based injuries are the causes of minor and severe blunt injuries. ${ }^{1,2}$

'Financial or Other Competing Interest': None.

Submission 24-09-2017, Peer Review 22-11-2017,

Acceptance 27-11-2017, Published 11-12-2017.

Corresponding Author:

Dr. Udaysridhar Mulgund,

H. No. 3, Block No. 1,

G. O. Quarters, KIMS,

Hubli-580021, Karnataka.

E-mail: udaymulgund@gmail.com

DOI: $10.14260 /$ jemds $/ 2017 / 1463$

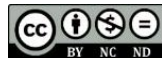

The majority of these injuries are sustained by active and productive individuals. ${ }^{1}$ Unfortunately, these injuries may all be often vision threatening and the lifestyle and future of these injured individuals are irrevocably altered.

Looking at the present scenario of working pattern and visual demands of patients and the use of sophisticated instruments, it has become mandatory on the part of an ophthalmologist to identify the various ocular structures involved due to blunt trauma, which may vary in severity from a simple corneal abrasion to an extensive rupture of globe, and provide satisfactory vision at its earliest of blunt injuries in a total perspective. It is essential to study not only recent injuries but also study the eyes which have sustained an injury at variable time intervals earlier.

Eye injuries are avoidable, if prevention is quite effective at work place, on the sports field, and in home. Patients and ophthalmologist must be aware of activities that incur high risk of eye injury and must take advantage of a protective 
eyewear that is available, which varies with the need of the patient and when used in proper manner can reduce eye injuries in most of the cases.

Ocular trauma is the most important preventable cause of blindness or partial loss of vision in more than half a million people worldwide, the commonest victim is young male.1,2

With the knowledge of circumstances of injury, their nature and the damage caused, early appropriate management can be taken, and preventive measures may be advised.

\section{Blunt Injuries Affecting Anterior Segment}

Anterior segment structures are effectively attached to the scleral wall, Iris is attached to the Iris root, lens anchored by the Zonules and the Ciliary body attaches to the scleral spur anteriorly. As the globe is deformed the Mechanical energy is transformed into hydraulic pressure wave. These forces act on the anterior segment structures forcing their untethered ends posteriorly while this is occurring, the attached peripheral ends are directed more equatorially with the expansion of globe in this dimension and the combination of events creates shearing forces, this forceful expansion of tissue results in tears.

Dante J Pieramici, Leonard M Parver ${ }^{3}$ (1995) Stated that there are 7 Rings of Tissues Those Expand Resulting in Tears-

1. Sphincter pupillae.

2. Iris base to ciliary body.

3. Anterior face of ciliary body.

4. Attachment of ciliary body to scleral spur.

5. Trabecular mesh work.

6. Lens Zonules.

7. Attachment of vitreous and retina.

\begin{tabular}{|c|c|}
\hline $\begin{array}{c}\text { Recently adopted } \\
\text { Classification }\end{array}$ & $\begin{array}{c}\text { Kuhn F. et. al,4 Standardized } \\
\text { classification of Ocular trauma. } \\
\text { Ophthalmo 1996 103-241. }\end{array}$ \\
\hline \multicolumn{2}{|c|}{ Ocular Trauma Classification } \\
\hline
\end{tabular}

\begin{tabular}{|c|c|}
\hline Closed globe Injury & $\begin{array}{l}\text { The Eye wall does not have a full } \\
\text { thickness wound. }\end{array}$ \\
\hline Open Globe Injury & $\begin{array}{l}\text { The Eye wall has a full thickness } \\
\text { wound, a through and through } \\
\text { injury. }\end{array}$ \\
\hline Ruptures & $\begin{array}{l}\text { Full thickness wound caused by } \\
\text { blunt impact and an inside out } \\
\text { mechanism. }\end{array}$ \\
\hline Laceration & $\begin{array}{l}\text { Full thickness wound by sharp } \\
\text { objects }\end{array}$ \\
\hline Penetrating Injury & $\begin{array}{l}\text { Single Laceration, usually by a } \\
\text { sharp object. }\end{array}$ \\
\hline $\begin{array}{l}\text { Perforating injury } \\
\text { Perforating }\end{array}$ & $\begin{array}{c}\text { Two full thickness lacerations } \\
\text { (Entrance and exit) usually caused } \\
\text { by sharp object or missile. }\end{array}$ \\
\hline
\end{tabular}

\section{MATERIALS AND METHODS}

\section{Study Design}

It is a prospective, interventional study. 100 cases of blunt trauma presented at Department of Ophthalmology, KIMS, Hubli, from September 2016 to August 2017 were prospectively studied. Visual acuity was recorded on
Snellen's chart, direct ophthalmoscopy, indirect ophthalmoscopy, slit-lamp examination were done. Relevant investigations were carried out such as X-ray orbit, fluorescein staining, lacrimal probing, syringing, gonioscopy, B-scan ultrasonography, CT scan and MRI scan in selected patients.

\section{Inclusion Criteria}

All Cases of Blunt Injury to the Eye

- Attending the outpatient department and

- Casualty department of KIMS Hospital are included.

\section{Exclusion criteria}

All Cases of

- Chemical injuries,

- Injuries with sharp instruments (penetrating, perforating) were excluded from the study.

- Patients who were having serious injuries which led them to life risk and needed priority management by other specialties were also excluded from the study.

Patients presenting with history of blunt injury to one or both eyes were selected from the out patients and in patients of ophthalmology Patients referred with blunt eye injury from the casualty department of KIMS, Hubli were selected.

The time interval between injury and consultation at these hospitals varied considerably. The earliest injury consultation interval being 2 hours and the longest being 10 days.

When a patient presented with a history of blunt injury. A detailed history regarding age, sex, occupation, causative agents, duration of injury, direction of force, signs and symptoms occurring following the injury were taken.

A detailed torch light examination was performed. Vision was recorded on Snellen's chart. Ophthalmoscopy was performed in cases wherever possible. Slit-lamp examination was performed in all the cases.

Gonioscopy was performed in all patients except patients with purely subconjunctival haemorrhage and corneal injury and severe lid injury, oedema which prevented from doing gonioscopy.

\section{Plain X-Ray}

X-ray of the skull in anteroposterior view, Water's (nosechin) position and parieto-orbital oblique projection were taken whenever necessary and in all medico-legal cases.

\section{B Scan}

Ultrasonography was performed in patients, where fundus could not be visualised and wherever suspected to have a vitreous haemorrhage, retinal detachment with or without media opacities.

\section{CT Scan Plain was done for the following cases:}

Orbital fracture, Road Traffic accident cases, in patients with history of fall and medicolegal cases with badly injured globe and adnexa and in desirable cases.

\section{MRI}

Magnetic Resonance Imaging Scans were done in all medicolegal cases and in other cases wherever it was necessary. 
RESULTS

Age Wise Distribution of Patients

\begin{tabular}{|c|c|c|}
\hline Age Group & No. of Cases & Percent \\
\hline Birth to 15 & 15 & 15 \\
\hline $16-25$ & 15 & 15 \\
\hline $26-35$ & 36 & 36 \\
\hline $36-45$ & 18 & 18 \\
\hline $46-55$ & 8 & 8 \\
\hline Above 55 & 8 & 8 \\
\hline \multicolumn{2}{|c|}{ Table 1. Age Incidence } \\
\hline \multicolumn{2}{|c}{} \\
\hline
\end{tabular}

\begin{tabular}{|c|c|c|}
\hline Sex & No. of Cases & Percent \\
\hline Male & 84 & 84.0 \\
\hline Female & 16 & 16.0 \\
\hline Total & $\mathbf{1 0 0}$ & $\mathbf{1 0 0 . 0 0}$ \\
\hline Table 2. Sex wise Distribution of Patients \\
\hline
\end{tabular}

\begin{tabular}{|c|c|c|}
\hline Source of Injury & No. of Cases & Percent \\
\hline Occupational injuries & 52 & 52 \\
\hline Sports \& Play & 23 & 22 \\
\hline RTA \& Assault & 22 & 22 \\
\hline Others & 3 & 3 \\
\hline Total & $\mathbf{1 0 0}$ & $\mathbf{1 0 0 . 0}$ \\
\hline
\end{tabular}

Table 3. Distribution of Cases According to Source of Injury

\begin{tabular}{|c|c|c|}
\hline Object & $\begin{array}{l}\text { No. of } \\
\text { Cases }\end{array}$ & Percent \\
\hline Stone & 18 & 18.0 \\
\hline Stick & 12 & 12.0 \\
\hline Iron rod & 7 & 7.0 \\
\hline Ball & 5 & 5.0 \\
\hline Fist & 12 & 12.0 \\
\hline $\begin{array}{c}\text { Metallic/Wooden } \\
\text { extraocular FB }\end{array}$ & 4 & 4.0 \\
\hline Branch of tree & 4 & 4.0 \\
\hline Bull gore & 6 & 6.0 \\
\hline Knob of door, Cup board & 4 & 4.0 \\
\hline Whip lash & 4 & 4.0 \\
\hline Cycle/Scooter handle & 4 & 4.0 \\
\hline Handle of handloom/lathe/Silk & 3 & 3.0 \\
\hline \multicolumn{3}{|l|}{ Reeling machine } \\
\hline Finger nail & 2 & 2.0 \\
\hline Pencil/Pen blunt end & 2 & 2.0 \\
\hline Racquet & 2 & 2.0 \\
\hline Tooth brush & 2 & 2.0 \\
\hline Others (RTA etc.) & 9 & 9.0 \\
\hline Total & 100 & 100.0 \\
\hline \multicolumn{3}{|c|}{ Table 4. Objects Causing Blunt Injury } \\
\hline
\end{tabular}

\begin{tabular}{|c|c|c|}
\hline Ocular Involvement & No. of Cases & Percent \\
\hline Periorbital region & 56 & 56.0 \\
\hline Lids & 65 & 65.0 \\
\hline Conjunctiva & 70 & 70.0 \\
\hline Cornea & 14 & 14.0 \\
\hline Hyphaema (AC) & 6 & 6.0 \\
\hline Iris & 20 & 20.0 \\
\hline Angle Recession & 6 & 6.0 \\
\hline Lens & 15 & 15.0 \\
\hline Posterior segment & 18 & 18.0 \\
\hline \multicolumn{2}{|c|}{ Table 5. Ocular Structures Involvement } \\
\hline
\end{tabular}

\begin{tabular}{|c|c|c|}
\hline Periorbital Lesions & No. of Cases & Percent \\
\hline Ecchymosis & 42 & 42 \\
\hline Lid oedema & 37 & 37 \\
\hline Laceration & 8 & 8 \\
\hline Emphysema & 4 & 4 \\
\hline Fracture & 9 & 9 \\
\hline \multicolumn{2}{|c|}{ Table 6. Distribution According to } \\
Periorbital Involvement \\
\hline
\end{tabular}

\begin{tabular}{|c|c|c|}
\hline Conjunctiva & No. of Cases & Percent \\
\hline Subconjunctival haemorrhage & 44 & 44 \\
\hline Chemosis & 20 & 20 \\
\hline Laceration & 6 & 6 \\
\hline Total & $\mathbf{7 0}$ & $\mathbf{7 0 . 0}$ \\
\hline Table 7. Distribution of Cases According to Conjunctival \\
Involvement \\
\hline
\end{tabular}

\begin{tabular}{|c|c|c|}
\hline Cornea & No. of Cases & Percent \\
\hline Abrasion & 5 & 5 \\
\hline Partial laceration & 2 & 2 \\
\hline Descemet's tear & 1 & 1 \\
\hline Oedema & 3 & 3 \\
\hline Ulcer & 1 & 1 \\
\hline Blood staining of cornea & 2 & 2 \\
\hline Total & 14 & $\mathbf{1 4 . 0}$ \\
\hline \multicolumn{2}{|c|}{ Table 8. Corneal Lesions } \\
\hline
\end{tabular}

\begin{tabular}{|c|c|c|}
\hline Iris & No. of Cases & Percent \\
\hline Iridodonesis & 3 & 3.0 \\
\hline Iridodialysis & 8 & 8.0 \\
\hline Synechiae & 3 & 3.0 \\
\hline Total & $\mathbf{1 4}$ & $\mathbf{1 4 . 0}$ \\
\hline \multicolumn{2}{|c|}{ Table 9. Distribution of Cases } \\
According to Iris Involvement \\
\hline
\end{tabular}

\begin{tabular}{|c|c|c|}
\hline Pupil & No. of Cases & Percent \\
\hline Miosis & 6 & 6 \\
\hline Mydriasis & 9 & 9 \\
\hline Total & $\mathbf{1 5}$ & $\mathbf{1 5}$ \\
\hline \multicolumn{2}{|c|}{ Table 10. Pupil Involvement } \\
\hline
\end{tabular}

\begin{tabular}{|c|c|c|}
\hline Lens involvement & No. of Cases & Percent \\
\hline $\begin{array}{c}\text { Subluxation of lens with and } \\
\text { without lenticular opacity }\end{array}$ & 2 & 2 \\
\hline Dislocation of lens & 1 & 1 \\
\hline Partial opacity & 7 & 7 \\
\hline Total opacity & 2 & 2 \\
\hline $\begin{array}{c}\text { Pure lenticular opacity } \\
\text { (Rosette) }\end{array}$ & 3 & 3 \\
\hline Total & $\mathbf{1 5}$ & $\mathbf{1 5}$ \\
\hline Table 11. Pattern of Lens Involvement \\
\hline
\end{tabular}




\begin{tabular}{|c|c|c|}
\hline Clinical Findings & $\begin{array}{l}\text { No. of } \\
\text { Cases }\end{array}$ & Percent \\
\hline \multicolumn{3}{|l|}{ Vitreous } \\
\hline $\begin{array}{l}\text { Vitreous herniation in to } \\
\text { anterior Chamber }\end{array}$ & 2 & 2 \\
\hline Vitreous haemorrhage & 3 & 3 \\
\hline \multicolumn{3}{|l|}{ Retina } \\
\hline Berlin's oedema & 3 & 3 \\
\hline Retinal oedema & 3 & 3 \\
\hline Retinal detachment & 4 & 4 \\
\hline \multicolumn{3}{|l|}{ Choroid } \\
\hline Choroidal haemorrhage & 1 & 1 \\
\hline Choroidal rupture & 2 & 2 \\
\hline Total & 18 & 18 \\
\hline
\end{tabular}

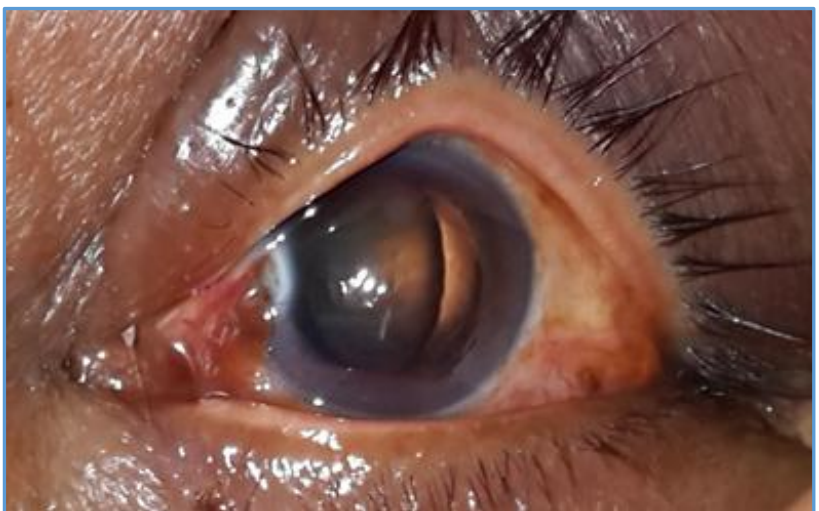

Figure 2. Subluxation of Lens

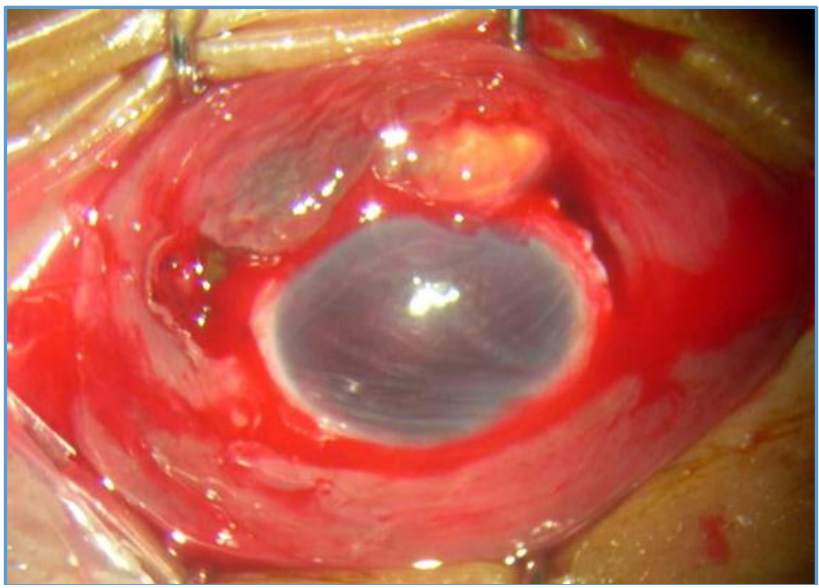

Figure 3. Blunt Trauma Globe Rupture

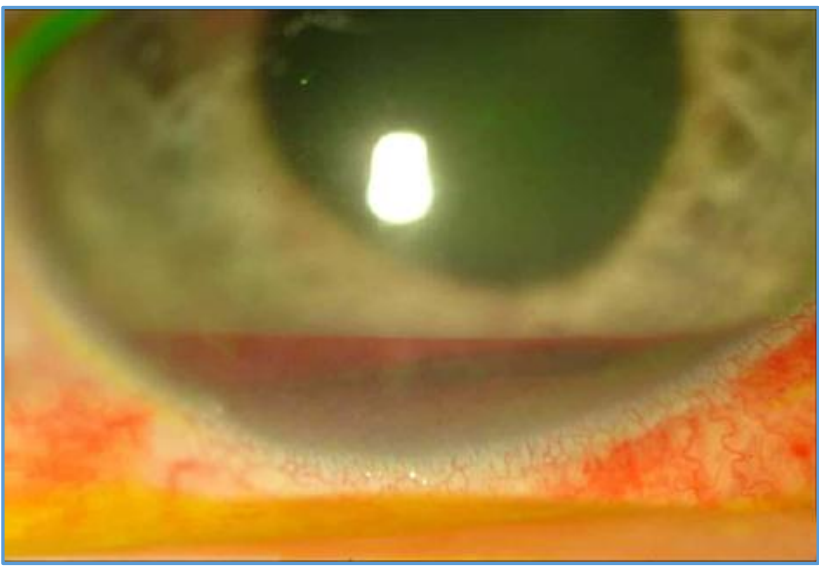

Figure 4. Hyphaema

\section{DISCUSSION}

\section{Age Incidence}

In this study consisting of 100 cases, the age range was from 3 months old child to 80 years old woman. Incidence of ocular injuries were found to be highest in the younger age group and children of 16 to 35 years (51\%).

Maximum cases were below the age group of 35 years. It has been observed that children and young adults are more prone to injuries, this may be due to more exposure to risk of blunt injuries, exposure and lack of awareness, regarding injuries among children.

According to Jain BS, Sony $\mathrm{SR}^{5}$ (1993), the maximum incidence of ocular injuries was seen in the age group of 16 to 30 years $(63 \%)$ and in children below 16 years $(23.2 \%)$. This is because children left to play unsupervised by their parents. 


\section{Sex Incidence}

There were $84 \%$ males and $16 \%$ females in this study, the male female ratio was $5.25: 1$, this nearly coincides with the study conducted by Eagling EM ${ }^{6}$ (1974), the male female ratio was 6.5:1.

\section{Occupational injuries}

Agriculture, the major bulk of our study which was followed by Sports and then Road Traffic Accidents and assault.

\section{Causative Agents/ Source of Injury}

The commonest causative agents were stones and sticks followed by injuries with cricket ball, rubber ball and fist. In this study, most common object causing blunt trauma to the eye was stone $(18 \%)$ followed by stick (12\%), fist $(12 \%)$, road traffic accident (9\%), iron rod (7\%), bull gore (6\%), ball $(5 \%)$, branch of tree $(4 \%)$, etc. The commonest mode of injuries was by stones. ${ }^{5}$

\section{Periorbital and Lid Involvement}

In this study, black eye or periorbital contusion was the most common clinical finding seen in 56 cases (56\%). This involved ecchymosis to the eye lid and or periorbital region. This is in accordance with the study conducted by Orlando and Doty JH (1996) in which they evaluated 125 patients with sports related ocular injuries and reported an incidence of $36 \%$ of lids of periorbital contusion injuries. Other findings included periorbital oedema (36.5 to 39\%), periorbital laceration 16 cases (8\%), crepitus (emphysema) (2 to 2.5\%), lid oedema (39\%), lid abrasion (7\%) and lid laceration (8\%). There were 44 patients with purely subconjunctival haemorrhage. 36 patients had subconjunctival haemorrhage associated with other findings.

\section{Corneal Findings}

After excluding 44 cases (eyes) of subconjunctival haemorrhage out of 100 cases, 14 eyes (14\%) had corneal findings, out of which 5 eyes had corneal abrasion, 3 eyes had corneal oedema, and 2 cases had blood staining of cornea. There were 2 patients with a partial thickness corneal tear of which 1 was in the superotemporal area just away from the limbus. In this study, there were 2 patients with blood staining of the cornea. 6 cases of hyphaema were present, most involved $1 / 3$ to $1 / 2$ of the anterior chamber, 2 cases had only marginal increase in IOP but none of them had significant raise in IOP.

\section{Iris and Pupillary Involvement}

Involvement of the iris and pupil constituted major number of clinical findings. Out of total cases, traumatic mydriasis was present in 9 eyes (9\%) which was the commonest followed by miosis in 6 eyes ( $6 \%$ ), synechiae in 3 cases (2\%). Our study corresponds to the study of 205 cases by Canavan and Archer ${ }^{7}$ in which 79 cases had iris and pupillary injuries.

\section{Lens}

15 eyes had lenticular involvement in the form of subluxation, dislocation, lenticular opacities with or without rupture of anterior capsule as opposed to the 52 eyes out of 212 in a study by Canavan and Archer. ${ }^{7}$ In this study, in 67 $(33.5 \%)$ eyes with lens and pupillary damages, 31 eyes had simultaneous lenticular damage as opposed to 44 and 79 eyes with lens or pupillary abnormalities in the study conducted by Canavan and Archer. ${ }^{7}$

\section{Posterior Segment Damage}

There were a total of 18 cases of posterior segment involvement. 3 eyes in this study had vitreous haemorrhage, 3 had Berlin's oedema. Siegfried found 167 cases $(12.5 \%)$ had Berlin's oedema. There were 4 cases of retinal detachment which could be appreciated on indirect ophthalmoscopy and was confirmed by B-Scan

A total of 3 cases of retinal oedema were observed, the vision returned to normal in most of the cases as the oedema subsided over a period of 1-2 months. 2 cases of choroidal rupture, 1 case of choroidal haemorrhage.

\section{Vision}

Out of total 100 cases, 42 eyes of subconjunctival haemorrhage had a best corrected visual acuity of $6 / 6$. The other two had pre-existing retinal pathology. Of the remaining 66 eyes, 20 eyes had a final visual acuity of $6 / 9,17$ eyes had a final visual acuity of $6 / 12$, and 5 eyes had a final visual acuity of 6/18, 2 cases had 6/24, 1 case had 6/36. 1 had less than 1/60, 2 had counting fingers to 2 metres, 1 had hand movement close to the face, 2 had $\mathrm{PL}^{+}+\mathrm{PR}, 1$ had 'following light movement' $\mathrm{PL}^{+}$, and 2 had no $\mathrm{PL}$.

\section{Extraocular Muscles and Nerves}

1 case $(1 \%)$ of traumatic total $3^{\text {rd }}$ nerve paralysis was seen, 1 case $(1 \%)$ of $4^{\text {th }}$ nerve paralysis was seen, 2 cases of combined $3^{\text {rd }}$ and $6^{\text {th }}$ nerve paralysis and 2 cases of isolated $6^{\text {th }}$ nerve paralysis were reported.

In traumatic $3^{\text {rd }}$ nerve paralysis, ocular movements were restricted in all the directions except abduction. Pupil in the affected eye was dilated and fixed.

\section{Corneoscleral Rupture}

There were 3 cases $(1.5 \%)$ of corneoscleral rupture starting from extreme periphery of the cornea and running through the sclera, these were associated with prolapse of the iris tissue. Suturing was done using 10.0 Vicryl after iris abscission/reposition.

This finding almost coincides with the study conducted by Kylstra JA, Lamkin JC, Runyan DK ${ }^{8}$ (1995) who have reported an incidence of $3.5 \%$ corneoscleral rupture.

\section{CONCLUSION}

It is clear from this study as well as other epidemiological studies conducted over past 15 years that ocular trauma is associated with varying degrees of loss of vision and earning capacity with social and economic consequences. This is an area for further research; additional investigation is also needed to develop and evaluate new interventions for prevention and management of all types of eye injuries.

Interdisciplinary approaches and community-based strategies will be important to make progress in this area of study to save and salvage vision.

From this study, we can infer that children and young adults are more prone to blunt ocular trauma, occupational injuries, and road traffic accidents constitute the main bulk of injuries.

Injury with stone was the most common (18 cases, 18\%), next comes stick injuries (12 cases, $12 \%$; agriculture related 
injuries) in causation of blunt ocular trauma.

In this study, anterior segment was more often affected (94 cases, 94\%).

Many of the injuries could have been prevented, if the patients had used protective eyewear during work or play.

We need to stress more on the importance of preventive measures by which incidence of these cases can be reduced.

In an unfortunate event of trauma, the patient must be seen as early as possible, referred to an ophthalmologist for adequate management.

Early referral, prompt evaluation and treatment will reduce the sight threatening complications in these cases.

Patients should be explained about the importance of protective measures like protective glass, helmets, etc. in occupations such as sports and travel.

\section{REFERENCES}

[1] Dondana L, Dondana R, Srinivas M, et al. Ocular trauma in an urban population in southern India: the Andhra Pradesh eye disease study. Clin Exp Ophthalmol 2000;28(5):350-58.
[2] Dannenberg AL, Parver LM, Fowler CJ. Penetrating eye injuries related to assault. The National Eye Trauma System Registry. Arch Ophtalmol 1992;110(6):849-52.

[3] Pieramici DJ, Parver PM. A mechanistic approach to ocular trauma. Ophthalmology Clinics of North America 1995;8(4):569-87.

[4] Kuhn F, Morris R, Witherspoon CD, et al. A standardized classification of ocular trauma. Ophthalmology 1996;103(2):240-3.

[5] Jain BS, Soni SR. Ocular injuries: an analytic study in a teaching general hospital. Indian J Ophthalmol 1987;35(3):112-6.

[6] Eagling EM. Ocular damage after blunt trauma to the eye. Its relationship to the nature of the injury. $\mathrm{Br} \mathrm{J}$ Ophthalmol 1974;58(2):126-40.

[7] Canavan YM, O'Flaherty MJ, Archer DB, et al. A 10-year survey of eye injuries in Northern Ireland 1967-76. Br J Ophthalmol 1980;64(8):618-25.

[8] Kylstra JA, Lamkin JC, Runyan DK. Clinical predictors of scleral rupture after blunt ocular trauma. Am J Ophthalmol 1993;115(4):530-5. 